\title{
Caracterizações do pensamento algébrico manifestadas por estudantes em uma tarefa da Early Algebra
}

\begin{abstract}
Daniele Peres da Silva
Angela Marta Pereira das Dores Savioli

Marinez Meneghello Passos

Resumo

Este artigo tem como objetivo identificar e analisar características do pensamento algébrico manifestadas em registros escritos de uma tarefa da Early Algebra de estudantes dos anos iniciais. Mais especificamente, procura-se compreender como esses estudantes do $5^{\circ}$ ano lidam com tarefas que podem promover o desenvolvimento do pensamento algébrico. As tarefas foram realizadas na perspectiva da Early Algebra, sendo esta uma área de pesquisa que visa uma abordagem para o ensino e a aprendizagem da álgebra inicial. Para organização e interpretação dos dados, foram empregados procedimentos da Análise de Conteúdo. Por meio das respostas apresentadas pôde-se evidenciar que embora as resoluções dos estudantes nem sempre estivessem corretas, elas apresentam indícios de pensamento algébrico. Podemos considerar que esses estudantes das séries iniciais demonstraram, por meio de suas produções escritas, ter condições de lidar e de desenvolver aspectos relacionados ao pensamento algébrico, mesmo não apresentando uma linguagem simbólica algébrica.
\end{abstract}

Palavras-chave: Pensamento Algébrico. Análise de Conteúdo. Early Algebra. Séries Iniciais.

\begin{abstract}
Characterizations of algebraic thinking manifested by students in a task Early Algebra

This article aims to identify and analyze characteristics of algebraic thinking in tasks applied to students of Elementary School I. More specifically, we seek to understand how the students of the 5 th year deal with tasks that can promote the development of algebraic thinking. The tasks were performed on Early Algebra perspective, that is an approach to teaching and learning early mathematics in deeper ways. For organizing and interpreting data, we used the procedures of Content Analysis. The answers provided by the students show that although the resolutions of the tasks were not always correct, they presented evidences of algebraic thinking. We can consider that these students demonstrated to be able to develop aspects related to algebraic thinking, although they did not presented an algebraic symbolic language.
\end{abstract} Grades.

Keywords: Algebraic thinking. Content Analysis. Early Algebra. Early 


\section{Introdução}

Neste artigo serão discutidos resultados de uma investigação que teve como objetivo identificar e analisar características do pensamento algébrico manifestadas em registros escritos de uma tarefa da Early Algebra de estudantes dos anos iniciais.

Para o desenvolvimento desta pesquisa, temos como objeto de estudo o pensamento algébrico manifestado por 37 estudantes do 5 o ano do Ensino Fundamental. Uma singularidade que se apresenta neste projeto é o fato de que essas crianças ainda não tiveram contato com uma linguagem simbólica algébrica ${ }^{1}$. Neste contexto a questão é recolocada: como então elas lidam com tarefas que podem promover o desenvolvimento desse pensamento? Para estruturar e sustentar nossas compreensões relativas a este fenômeno, consideramos os comportamentos, questionamentos e os registros escritos dos estudantes durante a aplicação da tarefa.

Para este artigo, por limitação de páginas e caracteres, trazemos somente uma dessas oito tarefas, que serviu de piloto e que estruturou o encaminhamento metodológico e interpretativo desenvolvido com as demais questões.

As tarefas foram aplicadas na abordagem da Early Algebra, que se configura em uma área de pesquisa que tem como objetivo o ensino e a aprendizagem da álgebra nos anos iniciais. Early Algebra é um programa criado em 1998, e que conta com uma equipe de psicólogos e educadores matemáticos que atuam com professores e estudantes em colaboração com escolas de Boston. Neste programa são construídos materiais didáticos e instrucionais a respeito da álgebra dos anos iniciais, abordando vários temas matemáticos, como, por exemplo, números, símbolos, comparações etc., focalizando a aprendizagem e o raciocínio dos estudantes.

Esses materiais são disponibilizados em um website que, além disso, apresenta algumas possibilidades de desenvolver aulas interativas, bem como "ideias para discussões" em sala de aula, a fim de enfatizar a necessidade de que introduzir a álgebra nas séries iniciais é altamente viável. Uma justificativa é que a compreensão de conceitos aritméticos demanda generalizações matemáticas e o entendimento dos princípios algébricos. Por conseguinte, aritmética e álgebra elementar estão intimamente interligadas.

Uma questão que tem levantado discussão, entre pesquisadores da área de Educação Matemática, é estabelecer em que momento da escolaridade seria adequado dar início ao desenvolvimento de tarefas que contenham na estrutura de sua resolução o pensamento algébrico

\footnotetext{
${ }^{1}$ Assumimos o termo "linguagem simbólica algébrica" como: a utilização de letras para generalizar uma situação-problema; letras como incógnita, variáveis; cálculo algébrico, como, por exemplo, (a $+b)^{2}=\left(a^{2}+2 a b+b^{2}\right)$ etc. (FIORENTINI; LORENZATO, 2006). Enfim, consideramos que um estudante tem contato ou habilidades com este tipo de linguagem se, por exemplo, escrever a equação $3 x+$ $6=4$ após ter lido "o triplo de um número somado a seis unidades resulta em quatro unidades".
}

R. B. E. C. T., vol 8, núm. 3, mai-ago.2015 ISSN - 1982-873X

DOI: Em andamento. 
subjacente. Em um movimento contínuo, viria outra questão: como definir o que seja "pensar algebricamente?".

Na próxima seção trazemos diversas considerações a respeito do pensamento algébrico, e alguns esclarecimentos sobre a álgebra que nos auxiliaram no desenvolvimento desta investigação.

\section{0 pensamento algébrico em foco}

Araújo (1999) observou que diversos pesquisadores estão preocupados com a educação algébrica que se tem ensinado aos estudantes, e esses declaram que talvez fosse apropriado começar a educação das crianças no pensamento algébrico, desde os ciclos iniciais.

Mediante algumas investigações pertinentes à área de Educação Matemática e que podem ser encontradas nas seguintes referências: Carpenter, Franke e Levi (2003); Brizuela e Schliemann (2004); Blanton e Kaput (2005); Lins e Kaput (2004); Carraher et al. (2006), é possível considerar a importância e a necessidade de se iniciar um trabalho estruturado no pensamento algébrico desde as séries iniciais da Educação Básica, da mesma forma que é dado o início da relação da aritmética com a álgebra nos primeiros ciclos escolares. Isso sustentado pelo fato de que o pensamento algébrico pode ser desenvolvido antes mesmo de o estudante apresentar uma linguagem simbólica algébrica.

Essas diversas pesquisas têm mostrado que crianças desde os nove e dez anos de idade podem desenvolver o pensamento algébrico, utilizar símbolos para generalizar relações aritméticas ou padrões geométricos, bem como fazer uso da noção algébrica para representar alguma relação.

Como indica Kieran (2004), o pensamento algébrico

\section{"[...] nas primeiras séries envolve o desenvolvimento de formas de pensar dentro} de atividades para as quais a linguagem simbólica pode ser usada como uma ferramenta, mas que não são exclusivas para a álgebra e que poderiam ser envolvidas sem o uso de uma linguagem simbólica, como, por exemplo, analisar relações entre quantidades, perceber mudanças, observar estruturas, resolver problemas, generalizar, modelar, justificar, provar e prever" (p.12, tradução nossa).

Da mesma forma, Fiorentini, Miorim e Miguel (1993, p.88) mencionam que: “[...] não há razão para sustentar uma iniciação relativamente tardia ao ensino-aprendizagem da Álgebra. Ao contrário, acreditamos que, desde as séries iniciais, o trabalho com esse tipo de pensamento se deve fazer presente na formação do estudante".

Compartilhando as mesmas ideias que dos autores mencionados anteriormente, Lins e Gimenez (1997, p.112) afirmam que: “[...] atividade aritmética envolve, naturalmente, um certo nível de generalidade" e "[...] quando dissemos que a diferença entre álgebra e aritmética era de 
tratamento, de foco, estávamos sugerindo não apenas que uma se beneficia da outra, como também que uma depende da outra" (p.113). Esses autores defendem a necessidade de introduzir a álgebra desde as séries iniciais, e, ainda, que ela seja desenvolvida juntamente com a aritmética. Em seus estudos, citam como exemplo outros países, com ênfase à Inglaterra, país em que para solucionar problemas com a aprendizagem da álgebra, iniciaram seu tratamento em séries posteriores, alcançando efeitos nada positivos.

De maneira semelhante, para Murray (2010), a “[...] álgebra não é separada da aritmética estudada nas séries elementares, mas sim, álgebra e aritmética estão integralmente conectadas" (MURRAY, 2010, p.74, tradução nossa).

Por conseguinte, crianças das séries iniciais seriam capazes de lidar com conceitos e utilizar notação algébrica, pois, como afirmam Carpenter, Franke e Levi (2003), destacando a importância da integração da aritmética com a álgebra nas séries iniciais do Ensino Fundamental, os estudantes podem "aprender aritmética de maneira produtiva de modo que esse conhecimento sirva de base para o aprendizado da álgebra" (CARPENTER; FRANKE e LEVI, 2003, p.137, tradução nossa).

Neste contexto, o pensamento algébrico pode ser desenvolvido antes de o estudante apresentar uma linguagem simbólica algébrica, pois isso advém, principalmente, quando:

"[...] a criança estabelece relações/comparações entre expressões numéricas ou padrões geométricos; percebe e tenta expressar as estruturas aritméticas de uma situação-problema; produz mais de um modelo aritmético para uma mesma situação-problema; ou, reciprocamente, produz vários significados para uma mesma expressão numérica; interpreta uma igualdade como equivalência entre duas grandezas ou entre duas expressões numéricas; transforma uma expressão aritmética em outra mais simples; desenvolve algum tipo de processo de generalização; percebe e tenta expressar regularidades ou invariâncias; desenvolve/cria uma linguagem mais concisa ou sincopada ao expressar-se matematicamente [...]" (FIORENTINI, FERNANDES e CRISTÓVÃO, 2005, p.5).

Diante do exposto, cabe destacar que concordamos com os autores pesquisados quanto à sustentação da ideia de que o pensamento algébrico pode ser desenvolvido antes de o estudante apresentar uma linguagem simbólica algébrica.

Como mencionado, outra discussão presente nas publicações da área de Educação Matemática é a necessidade de estabelecer o que seja "pensar algebricamente", principalmente pelo fato de não existir até o momento um consenso para os integrantes da área em questão. Fato que aponta para a seguinte consideração: para o termo "pensamento algébrico" não há ao certo uma definição ou então um ponto de vista assumido entre a comunidade de educadores matemáticos, uma vez que este pensamento está associado a diversas conotações (KIERAN, 2004). 
No entanto, apesar de não haver um consenso para o que seja "pensar algebricamente", expressão que pode ser observada em Lins e Gimenez (1997), alguns autores, a fim de estabelecer uma acepção para esse pensamento, trazem elementos que o caracterizam (KIERAN, 2004).

Diante dessa dificuldade de definir precisamente o que seja "pensar algebricamente", para o desenvolvimento desta investigação e durante a interpretação das resoluções dos estudantes, informamos que serão consideradas as seguintes características para identificar manifestações de pensamento algébrico. Desta forma consideramos que este pensamento:

- Pode manifestar-se em qualquer nível escolar, uma vez que não tem como pré-requisito que o estudante apresente uma linguagem simbólica algébrica;

- Enfim, este pensamento envolve: estabelecimento de relações; utilização de diferentes notações para uma mesma situação-problema; estabelecimento de regularidades; algum processo de generalização; compreensão de propriedades matemáticas importantes como, por exemplo, a comutatividade na adição, agrupamento, classificação, ordenação etc..

Mesmo não tendo intenção de discutir nesta investigação a respeito de teorias que tratam sobre o desenvolvimento de processos de pensamento na criança, é importante uma breve reflexão sobre a evolução do raciocínio infantil, e como ocorre esse processo (BRIZUELA, 2006).

Vygotsky e Piaget abordaram o tema em questão, dedicando-se em compreender como ocorre o processo de aprendizagem no indivíduo.

Vygotsky foi um psicólogo importante na sua área, buscava compreender a conexão entre os conceitos que os sujeitos desenvolvem e o que falam ou escrevem (VYGOTSKY, 2001). Durante suas investigaçãoes desenvolveu várias considerações importantes a respeito da origem de nossas concepções. Dentre elas, considera que entre pensamento e linguagem existe uma forte relação, de modo que a linguagem tem uma ação fundamental tanto na formação como também no comportamento do indivíduo. Para o autor é a partir da interação com o meio que a pessoa vai construindo sua identidade, ou seja, o pensamento de uma pessoa estrutura-se dependendo da cultura e dos hábitos sociais em que esta se desenvolve.

Piaget, um dos pensadores mais importantes do século XX, focou-se nas particularidades distintivas do pensamento das crianças, e foi o primeiro a "[...] estudar sistematicamente a percepção e a lógica infantis [...]" (VYGOTSKY, 2001, p.27). Segundo suas investigações, a construção do conhecimento é um processo interior, uma costrução pessoal, em que o sujeito a partir dos conhecimentos prévios vai organizando e formando novos conceitos. Nesta teoria o desenvolvimento é algo interno, enquanto a aprendizagem é gerada por condições externas.

Recentemente, a educadora e pesquisadora Brizuela (2006) afirmou que investigações com crianças da Educação Infantil e do Ensino Fundamental apontam a "[...] necessidade de pensarmos sobre as notações matemáticas como uma parte essencial das compreensões e dos conceitos 
matemáticos, e como algo que vai muito além de habilidades motoras finas [...]" (BRIZUELA, 2006, p. 118). Concordamos com a autora e ressaltamos esta mesma necessidade de reflexão para o pensamento algébrico elementar.

Estando posto o que assumimos para considerar uma forma de pensar algebricamente, na sequência apresentaremos alguns esclarecimentos relativos à Análise de Conteúdo e os procedimentos metodológicos adotados na pesquisa. E, posteriormente, traremos diversas interpretações possibilitadas pelas resoluções apresentadas pelos estudantes, sempre considerando os referenciais teóricos e metodológicos assumidos para o desenvolvimento desta investigação.

\section{Procedimentos metodológicos e a coleta de dados}

Tanto para a organização, como para a análise e a interpretação dos dados, o método investigativo adotado para o desenvolvimento desta pesquisa foi a Análise de Conteúdo, que se configura por ser uma das modalidades de pesquisa qualitativa.

Na continuidade apresentaremos uma síntese a respeito da Análise de Conteúdo a fim de justificar sua escolha, destacando suas contribuições e facilitações para os encaminhamentos relativos a esta pesquisa.

Bardin (2004) apresenta a Análise de Conteúdo como:

"[...] um conjunto de técnicas que permitem a exploração e análise das informações de uma pesquisa. É por meio da Análise de Conteúdo que é possível retirar informações contidas num texto, interpretá-las podendo assim relacionálas ao contexto em que se deu determinada produção. Esta forma de análise leva o pesquisador, depois de muito estudo, a criar categorias, agrupando unidades de análise semelhantes, fazendo inferências sempre que necessário e possível" (BARDIN, 2004, p.26).

Este método de análise tem como finalidade conduzir a compreensões do fenômeno em estudo, bem como descrever os sujeitos, o contexto e o intervalo de tempo em que tal evento ocorre, o que nos leva a uma capacidade de entendimento do teor das mensagens (neste caso registros das resoluções das tarefas) em estudo.

Em resumo, a Análise de Conteúdo pode ser estruturada em torno de três polos cronológicos: a pré-análise; a exploração do material e o tratamento dos resultados, considerando pertencente a esse último polo o processo interpretativo e uma projeção das considerações do pesquisador relativa ao fenômeno que pesquisa.

A pré-análise constitui-se como um primeiro contato com os dados, um primeiro olhar naquilo que se transformará (total ou parcialmente) em seu objeto de pesquisa. É o momento de

R. B. E. C. T., vol 8, núm. 3, mai-ago.2015 ISSN - 1982-873X

DOI: Em andamento. 
organização do material que será submetido à análise. Momento em que surgem as primeiras impressões, diante das quais é possível estabelecer hipóteses e elaborar os objetivos que irão embasar as ações investigativas.

Este primeiro olhar recebe a denominação de "leitura flutuante" (BARDIN, 2004), é o período em que surgem as impressões e as orientações prévias do que se constituirá, posteriormente, como movimentos na pesquisa. Depois desse momento de 'mergulho nos dados', o pesquisador consegue estabelecer 'o universo' a ser investigado, bem como já possui condições de evidenciar quais são as informações essenciais desse universo, que podem contribuir com a resposta às suas indagações. Diante desta delimitação tem-se constituído o corpus da pesquisa - o conjunto de informações, o banco de dados, formado, essencialmente, de produções textuais, sendo os textos entendidos como produções linguísticas, referentes a determinado fenômeno, incluindo imagens e outras produções.

Cabe destacar que a composição de um corpus está sujeita a diversas escolhas, possibilidades de seleção e justificação de regras (algumas já estabelecidas teoricamente e, outras, que carregam as condições singulares de pesquisa relacionadas aos dados coletados por esse pesquisador no momento de sua busca no campo investigativo). Todas essas questões precisam ser consideradas a fim de que tenhamos um conjunto de documentos adequado para serem analisados e que produzam resultados coerentes e com significação em relação ao que se investiga.

Segundo Bardin (2004), as principais regras estabelecidas (teoricamente) são:

- Regra da exaustividade - esta regra afirma que não se pode deixar de fora qualquer elemento que seja importante à pesquisa, por exemplo, por dificuldade de acesso.

- Regra da representatividade - os elementos para a investigação, ou seja, a amostragem deve ser representativa do universo inicial, uma vez que os resultados alcançados para a amostra serão generalizados ao todo investigado.

- Regra da homogeneidade - os documentos escolhidos para investigação precisam ser homogêneos, ou seja, devem obedecer aos mesmos critérios de escolha.

- Regra de pertinência - os elementos selecionados para a pesquisa necessitam ser apropriados, isto é, precisam ter condições de atender ao objetivo da investigação.

Quanto à escolha do corpus, o conjunto de informações pode existir previamente ou ser produzido ao longo do processo da pesquisa. Assim sendo, após delimitar o corpus, de modo que atenda às regras mencionadas, pode-se dar início à pré-análise.

No que diz respeito à exploração do material, esta etapa é muitas vezes longa e retomável, pois é composta de procedimentos aplicados aos dados, entre eles a evidenciação de unidades de busca que podem tornar-se unidades de registros e, posteriormente, unidades de pesquisa. Esta etapa ainda é composta por operações de codificação ou enumeração dessas unidades que, em função de regras previamente formuladas, e um possível reagrupamento dessas unidades (que 
também podem ser considerados fragmentos), são idealizadas na tentativa de propor uma nova ordem que contribua com a compreensão que se almeja.

Esta fase é muito importante, tendo em vista que no desenvolvimento da pesquisa o pesquisador retorna muitas vezes ao corpus constituído. Sendo assim, esse conjunto de documentos em processo analítico precisa estar sempre organizado e as unidades e/ou fragmentos dele capturados precisam ter sua procedência deveras identificada.

Quanto aos agrupamentos elaborados, cabe destacar que essa forma de composição pode ser estabelecida a priori - em função dos referenciais adotados - ou pode emergir dos dados em interpretação. São desses agrupamentos das informações por proximidade teórica ou interpretativa que surgirão as categorias relacionadas ao fenômeno que se busca compreender. Categorias essas que possuem a função de auxiliar o pesquisador na estruturação do texto que comunicará seus resultados analíticos.

Cabe destacar que a acomodação das unidades de significado (identificadas pelo pesquisador) em categorias não é uma etapa obrigatória da Análise de Conteúdo, contudo, mesmo que as categorias não sejam geradas ou não se evidenciem, a maioria dos procedimentos de análise organiza-se em torno de um processo de categorização (às vezes não explícito nem para aquele que pesquisa).

A categorização constitui-se como um processo longo e exigente, de busca de interpretações, de novos significados e supostos sentidos ${ }^{2}$, de refinamento, na tentativa de sintetizar as informações, bem como estabelecer relações entre elas por meio de categorias. Este é um dos procedimentos (não descritivos) da Análise de Conteúdo que auxilia na busca de novas compreensões dos fenômenos investigados.

Ao longo da pesquisa, as categorias vão se refinando a fim de se tornarem cada vez mais precisas - relacionadas ao fenômeno -, considerando que serão apresentadas, posteriormente, na forma de textos interpretativos. Durante este refinamento, as categorias precisam adequar-se a algumas características, para ao final da investigação e da composição das considerações referentes à busca objetivada, validem os resultados encontrados. Entre essas características encontram-se algumas que consideramos nesta pesquisa: a exclusão mútua; a homogeneidade; a pertinência; a objetividade, a fidelidade e a produtividade.

\footnotetext{
${ }^{2}$ Estamos considerando aqui, à maneira como o faz Vygotsky, que enquanto o significado consiste em um núcleo relativamente estável de compreensão da palavra, compartilhado por um grupo grande de pessoas, o sentido é particular, dependente do contexto do uso da palavra e remete às vivências afetivas do indivíduo, ou seja: o sentido da palavra liga seu significado objetivo ao contexto de uso da língua e aos motivos afetivos e pessoais de seus usuários (OLIVEIRA, 1993, p.50, assinalamentos da autora).
}

R. B. E. C. T., vol 8, núm. 3, mai-ago.2015 ISSN - 1982-873X

DOI: Em andamento. 
A exclusão mútua garante que cada elemento não pertença a mais de uma categoria, embora, em certos casos, pode ser desconsiderada, mediante esclarecimentos e justificativas, uma vez que determinada unidade de pesquisa pode ser interpretada por diferentes perspectivas. A homogeneidade estabelece que se tenha um único princípio de classificação, organização e edificação das categorias, ou seja, deve-se pensar de uma maneira homogênea, contínua e integrada a geração das categorias, garantindo essa característica. A pertinência das categorias está diretamente relacionada ao material selecionado para estudo, isto é, os elementos capturados para compor o corpus investigativo, bem como as unidades de pesquisa pinçadas desse corpus precisam ter condições de responder ao que se pergunta mediante o quadro teórico definido inicialmente, para tal processo de investigação. A objetividade e fidelidade garantem que as categorias sejam codificadas segundo uma mesma caracterização, mesmo que submetidas a diferentes movimentos interpretativos. Por fim, a última condição expõe que uma categoria é produtiva se provê resultados fecundos, ou seja, se permitir a emergência de novas formas de perceber e compreender o fenômeno em investigação.

Diante do exposto, a validação das categorias sustenta sua relação com o fenômeno e com os temas estudados, contribuindo para a compreensão daquilo que se procura elucidar. Cabe relevar também que este movimento procedimental requer a dedicação e o envolvimento do pesquisador, sendo que a princípio ele parte de um conjunto de informações desorganizadas (ou organizadas de uma maneira que não contribui com a resposta à sua questão de pesquisa) e caminha em direção a certa organização que possa amparar suas considerações e teorizações sobre o fenômeno.

No terceiro polo cronológico, polo em que as inferências, as interpretações e os resultados são o foco, é o momento de o pesquisador tecer suas considerações a respeito do fenômeno que pesquisa. É o momento de comunicar seus achados e, por meio de textos, expressar suas principais ideias sustentadas pela análise realizada. Nesse ou nesses textos produzidos pelo pesquisador ele apresenta seus argumentos, tendo por finalidade comunicar as compreensões e os significados alcançados, bem como os significados e os sentidos construídos a partir das análises.

Com relação ao pesquisador, este precisa ter um papel ativo durante todo o processo investigativo, assumindo-se como o responsável pela construção dos significados que emergirem do corpus de pesquisa. Cabe destacar que a produção de suas considerações sobre o fenômeno em questão sempre estará tingida da subjetividade do pesquisador, de suas impressões, de seu esforço pela procura de sentidos e compreensões mais aprofundadas.

Na sequência, para finalizar esta seção, trazemos algumas informações relativas à coleta de dados, explicitando a tarefa aqui trabalhada e alguns detalhes considerados para esse desenvolvimento. 
Em sua totalidade, nosso acervo é composto por oito tarefas desenvolvidas por 35 estudantes do 5o ano do Ensino Fundamental. Para este artigo descrevemos os procedimentos de uma única tarefa - a de número 6. Por conseguinte, nosso corpus fica constituído por 35 registros que trazem as resoluções apresentadas pelos estudantes para a tarefa 6 .

No desenvolvimento das tarefas, os estudantes foram direcionados a resolverem individualmente cada uma delas. Indicamos que, antes da aplicação de cada tarefa, não se realizou uma discussão com a turma, de modo que resolvessem sem qualquer interferência ou comentário o que havia sido proposto. Essa atitude foi considerada a fim de não influenciá-los nas estratégias, caminhos e possibilidades quaisquer com relação à resolução do que era solicitado em cada caso.

Os documentos que orientaram o desenvolvimento das interpretações aqui apresentadas foram o diário de campo (construído pelos pesquisadores durante e após cada encontro com os estudantes) e os registros escritos dos estudantes, quando da resolução das tarefas propostas.

Informamos que o diário de campo tornou-se importante para esta investigação, pois por meio dele foi possível registrar informações fundamentais do contexto em questão, por exemplo, indagações, afirmações dos estudantes durante a resolução da tarefa. Ele foi adotado desde o princípio da pesquisa, pois estávamos inspirados nas colocações de Fiorentini e Lorenzato (2006), quando afirmam que o diário de campo é um dos instrumentos mais ricos na coleta de informações, pois é "[...] nele que o pesquisador registra observações de fenômenos, faz descrições de pessoas e cenários, descreve episódios ou retrata diálogos" (p.118-119). Além dos registros escritos, os quais contemplam as resoluções dos 37 estudantes investigados, analisamos as informações coletadas no diário de campo.

A seguir incluímos a tarefa seis - analisada neste artigo - e que sustentou a análise de todas as demais (não apresentadas neste momento por questão de espaço). Após a apresentação da tarefa, listaremos os objetivos indicados pelo site da Early Algebra, ambiente virtual de que a tarefa foi selecionada.

DOI: Em andamento. 


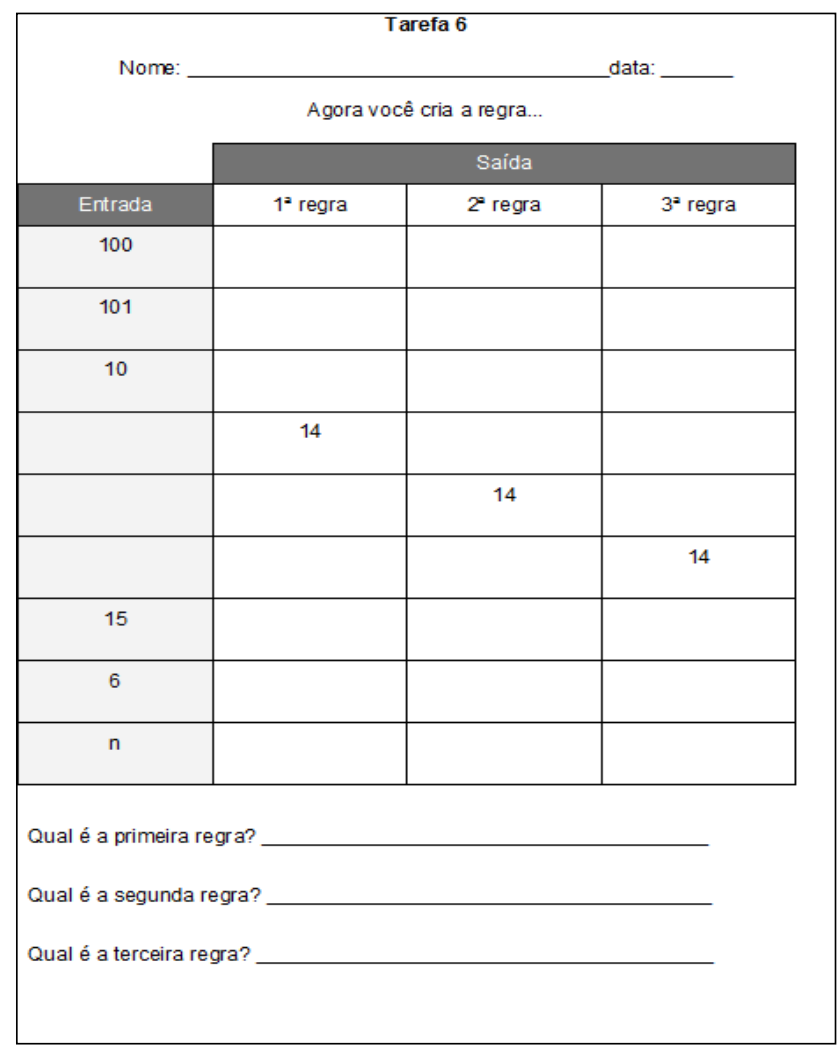

Tarefa 6

(Fonte: http://ase.tufts.edu/education/earlyalgebra/default.asp)

Para o que foi proposto nesta tarefa, os objetivos relacionados no site são: interpretar funções simples de adição e suas inversas; interpretar e produzir tabelas; produzir expressões algébricas. Essa explicitação dos objetivos estará relacionada diretamente com as primeiras leituras realizadas nos registros dos estudantes, e nos acompanha por todo o processo de categorização, bem como incide sobre nossas compreensões.

Tendo em mãos os registros dos estudantes, demos início aos procedimentos indicados pela Análise de Conteúdo, cujos encaminhamentos e interpretações descrevemos na próxima seção.

\section{O processo de organização e interpretação dos dados}

Em um momento inicial realizamos a "leitura flutuante" dos registros, buscando verificar o que os estudantes haviam registrado, porém sem qualquer objetivação. Em um segundo momento, ainda durante a pré-análise, procuramos por registros que nos orientassem quanto aos objetivos propostos para aquela tarefa (a tarefa 6 ) - movimento este que já havia ocorrido para as demais. 
Considerando que esta era a sexta tarefa de uma sequência de oito a que os estudantes foram submetidos, nós a selecionamos para construir uma metodologia analítica. Passamos então à exploração do material (35 registros dos estudantes que traziam a resolução da tarefa 6).

Essa fase foi intensamente impregnada pelos dados e a partir desse movimento surgiram as primeiras unidades de registro - referentes a esta tarefa - e que, por extensão, subsidiaram movimentos semelhantes com relação às demais tarefas investigadas.

Essa foi uma etapa fundamental para o ciclo de pesquisa que consumou os resultados aqui apresentados.

A partir deste momento passaremos a descrever unicamente os procedimentos realizados na análise da tarefa 6 . Antes de iniciarmos os agrupamentos dos registros semelhantes nós os codificamos um a um, relacionando-os com cada um dos estudantes que os haviam registrado. Sendo assim, juntamente a cada registro encontraremos códigos como estes - E.1, E.2, E.3, [...], E.35, que significam estudante de número 1, estudante de número 2 até estudantes de número 35.

Após diversas tentativas de exploração dos registros e simulações, quanto aos agrupamentos dos que se assemelhavam ou representavam conduções de resolução próximas, buscamos descrever o que sistematizava aqueles grupos e deste procedimento criamos diversas unidades e subunidades de registro, as quais representam uma síntese das estratégias utilizadas pelos estudantes na resolução da tarefa.

Cabe destacar que toda produção escrita foi cuidadosamente descrita (desenhos, rabiscos, operação, observação, descrição, representação etc.) e destas descrições é que foram gerados os conjuntos em que acomodaríamos as unidades de registro.

\section{$\underline{\text { Tarefa } 6}$}

Foram identificados nesta tarefa 35 registros escritos, ou seja, todos os estudantes se manifestaram de forma escrita na intenção de solucionar o solicitado.

\section{Agrupamentos}

A seguir apresentamos os agrupamentos possibilitados por esse movimento interpretativo da resolução da tarefa 6 , descrevendo o que consideramos como pertinente a cada agrupamento e a cada subagrupamento, em alguns casos.

A. Completa o quadro utilizando um padrão. Aplica as regras criadas ao valor da coluna anterior e não ao valor de entrada, ou seja, apenas a primeira regra é aplicada ao valor de entrada.

$\mathbf{A}_{1}$ - Completa o quadro aplicando as regras criadas ao valor da coluna anterior e não ao valor de entrada, e para o valor de entrada ' $n$ ', expressa uma linguagem simbólica algébrica. Demonstra generalização. Descreve as regras que criou. 
$\mathbf{A}_{\mathbf{2}}$ - Completa o quadro aplicando as regras criadas ao valor da coluna anterior e não ao valor de entrada, e para o valor de entrada ' $n$ ', completa com números, não demonstrando generalização. Descreve as regras que criou.

$\mathbf{A}_{3}$ - Completa parcialmente o quadro aplicando as regras criadas ao valor da coluna anterior e não ao valor de entrada. Porém, não dá continuidade na regra ao completar o quadro. Não explicita ou descreve as regras criadas.

B. Não evidencia um padrão ao completar o quadro e ou ao descrever as regras criadas.

C. Completa o quadro utilizando um padrão. Aplica as regras criadas aos valores de entrada, não recorre ao valor da coluna anterior.

$\mathrm{C}_{1}$ - Completa o quadro com as regras criadas para os valores de entrada. No entanto, para o valor de entrada ' $n$ ', completa com números ou então não completa, não demonstrando generalização. Ainda, para os campos sem valor de entrada, deixa em branco. Descreve as regras do quadro.

$\mathbf{C}_{2}$ - Completa o quadro com as regras criadas para os valores de entrada. No entanto, para o valor de entrada ' $n$ ', completa com números ou então não completa, não demonstrando generalização. Descreve as regras do quadro.

$\mathbf{C}_{3}$ - Completa o quadro com as regras criadas para os valores de entrada. No entanto, para o valor de entrada ' $n$ ', expressa uma linguagem simbólica algébrica. Demonstra generalização. Descreve as regras do quadro.

\section{Outros.}

A seguir apresentamos um quadro em que foram quantificados os registros dos estudantes segundo os agrupamentos descritos anteriormente, ou seja, os registros dos estudantes E.25 e E.33 foram alocados no agrupamento de código $A$ no subagrupamento $A_{1}$ e assim por diante.

Quadro 1-Agrupamentos dos registros escritos referentes à tarefa 6

\begin{tabular}{|r|l|}
\hline & Quantidade de registros em cada agrupamento \\
\hline $\mathbf{A}_{\mathbf{1}}$ & E.25, E.33 \\
\hline $\mathbf{A}_{\mathbf{2}}$ & E.2, E.4, E.7, E.10, E.12, E.13, E.15, E.17, E.19, E.20, E.22, E.26, E.27, E.28, E.31, \\
\hline $\mathbf{A}_{\mathbf{3}}$ & E.1 \\
\hline $\mathbf{B}$ & E.3, E.5, E.11, E.16, E.18, E.23 \\
\hline $\mathbf{C}_{\mathbf{1}}$ & E.6, E.8, E.21 \\
\hline $\mathbf{C}_{\mathbf{2}}$ & E.9, E.24, E.29, E.30 \\
\hline $\mathbf{C}_{\mathbf{3}}$ & E.14 \\
\hline
\end{tabular}


(Fonte: Autores do artigo, segundo dados de pesquisa)

Para esta tarefa, a de número 6 , os agrupamentos foram excludentes, ou seja, cada resolução só se encaixa em um agrupamento. Esta escolha pela característica da exclusão não foi prévia, ela foi constatada após a interpretação dos dados e sua acomodação nos agrupamentos, fato esse que não necessariamente ocorreu quando do estudo das outras tarefas que aqui não foram exploradas.

Neste momento da investigação focamos nos agrupamentos anteriormente descritos, a fim de construirmos uma primeira análise interpretativa referente às resoluções dos estudantes com relação a esta tarefa. Partindo dos registros escritos, do diário de campo e da fundamentação teórica adotada, desenvolvemos algumas reflexões que nos conduzissem a interpretações sobre a produção escrita dos participantes, considerando o objetivo da pesquisa, que se concentra em levantar considerações acerca de aspectos que envolvem características de pensamento algébrico nas produções escritas de estudantes dessa série inicial em estudo.

Por meio do processo de análise foi revelado que, embora as resoluções dos estudantes nem sempre estivessem corretas, elas confirmam indícios de pensamento algébrico, bem como algumas das características descritas anteriormente nos agrupamentos e subagrupamentos prévios. Em geral as resoluções dos estudantes investigados verbalizam processos de pensamento matemático.

Compartilhando com o que afirma Kieran (2004), o pensamento algébrico muitas vezes pode não apresentar necessariamente ferramentas de uma linguagem simbólica, porém pode auxiliar como base à introdução da álgebra nas séries posteriores.

Com relação a esta tarefa, os estudantes deveriam criar as regras e segui-las de acordo com os valores do quadro. Assim, durante a resolução surgiram alguns questionamentos: "Como eu vou criar a regra?", "que regra professora?", "eu não sei, explica!".

A partir destas indagações fica evidente que a tarefa apresentada era distinta do que muitos deles estavam habituados a realizar (em geral, realizavam tarefas com instruções no enunciado, as quais indicavam o caminho a seguir), pois houve uma considerável alteração pelo fato de que deveriam resolvê-la sem qualquer explicação do professor presente na sala de aula no momento desta aplicação e, ainda, que a tarefa é 'aberta' para várias interpretações, não indicando, por exemplo, que tipo de regra criar.

Também é importante observar que, em geral, ao completarem o quadro, os estudantes aplicaram as regras aos valores da coluna anterior e não ao valor de entrada, sendo esta outra possibilidade de resposta, uma vez que, como mencionado, a tarefa é 'aberta' para várias interpretações. Em dezenove resoluções encontramos este padrão ao concluírem o quadro, ou seja, mais da metade dos estudantes em análise adotou tal procedimento. Cabe explicitar que a

R. B. E. C. T., vol 8, núm. 3, mai-ago.2015 ISSN - 1982-873X

DOI: Em andamento. 
tarefa anterior (em anexo), a de número 5, traz a informação de que as regras seriam aplicadas aos valores de entrada.

A seguir foram apresentados exemplos de resoluções (dos estudantes E.7, E.10, E.13 e E.15) que se acomodam no subagrupamento $A_{2}$, aquele que possui maior quantidade de registros nele alocado e que estão relacionados aos comentários do parágrafo anterior.

Cabe destacar que, mesmo esses registros estando alocados no subagrupamento $A_{2}$, as estratégias dos estudantes possuem particularidades não generalizáveis e que serão consideradas em interpretações anteriores, quando da construção de categorias que contribuirão com a compreensão do que questionamos sobre a elaboração do pensamento algébrico desses estudantes.

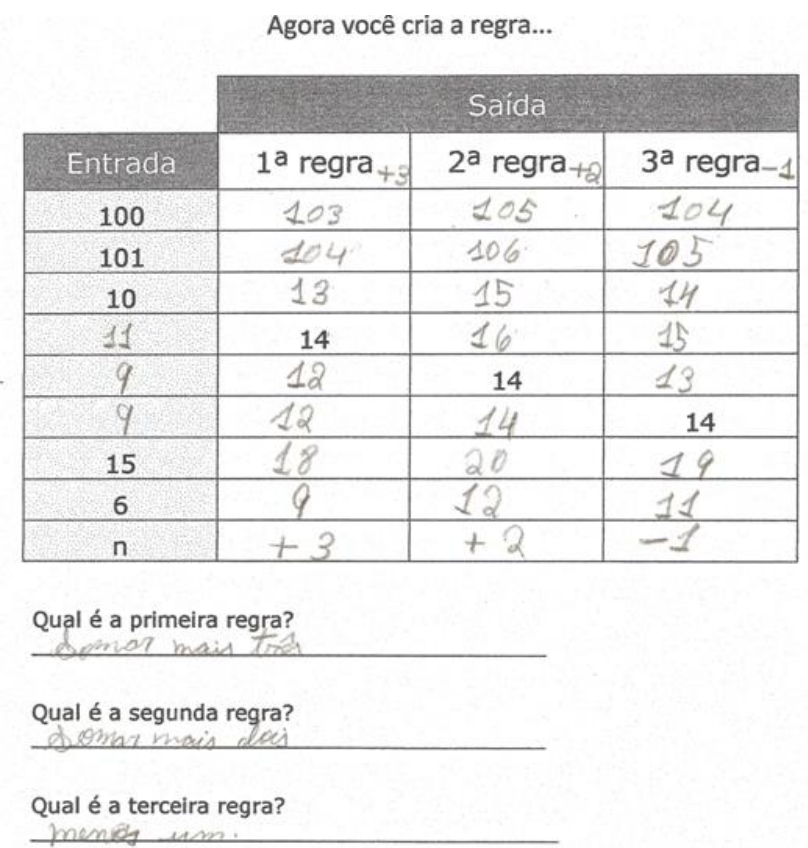

Figura 1 - Registro escrito (tarefa 6) do participante E.7

(Fonte: Autores do artigo, segundo dados de pesquisa)

${ }^{3}$ Indicamos que não foi nossa intenção neste artigo apresentar registros representantes de todos os 8 agrupamentos e/ou subagrupamentos que estruturam o Quadro 1. Destacamos esses pertencimentos para ilustrar tais acomodações e para justificar movimentos posteriores de pesquisa, que culminam na constituição de categorias.

118 DOI: Em andamento.

R. Bras. de Ensino de C\&T 


\begin{tabular}{|c|c|c|c|}
\multicolumn{2}{c}{} & \multicolumn{3}{c|}{ Agora vocē cria a regra... } \\
\cline { 2 - 4 } & \multicolumn{3}{c|}{ Saida } \\
\hline Entrada & $1^{\text {a }}$ regra & $2^{\text {a }}$ regra & $3^{\text {a }}$ regra \\
\hline 100 & $103^{\prime}$ & 106 & 109 \\
\hline 101 & 104 & 107 & 110 \\
\hline 10 & 13 & 16 & 19 \\
\hline 11 & 14 & 17 & 20 \\
\hline 8 & 11 & 14 & 17 \\
\hline 5 & 8 & 11 & 14 \\
\hline 15 & 18 & 21 & 24 \\
\hline 6 & 9 & 12 & 5 \\
\hline$n$ & 103 & 106 & 109 \\
\hline
\end{tabular}

Qual é a primeira regra?

Qual é a segunda regra?

Qual é a terceira regra?

Figura 2 - Registro escrito (tarefa 6) do participante E.10

(Fonte: Autores do artigo, segundo dados de pesquisa)

\begin{tabular}{|c|c|c|c|}
\cline { 2 - 4 } \multicolumn{1}{c|}{} & \multicolumn{3}{c|}{ Saida } \\
\hline Entrada & $1^{\text {a regra }+3}$ & $2^{\text {a }}$ regra -5 & $3^{\text {a }}$ regrar2 \\
\hline 100 & 103 & 98 & 196 \\
\hline 101 & 104 & 99 & 198 \\
\hline 10 & 15 & 10 & 20 \\
\hline 11 & 14 & 09 & 18 \\
\hline 16 & 19 & 14 & 28 \\
\hline 7 & 10 & 7 & 14 \\
\hline 15 & 18 & 13 & 26 \\
\hline 6 & 9 & 3 & 8 \\
\hline$n$ & 1 & 2 & 3 \\
\hline
\end{tabular}

Qual é a primeira regra?

$\begin{array}{lr}\text { Qual é a primeira regra? } & \text { Loman was ties } \\ \text { Qual é a segunda regra? } & \frac{05}{098}\end{array}$

Qual é a segunda regra?

$\frac{05}{098}$

Qual é a terceira regra?

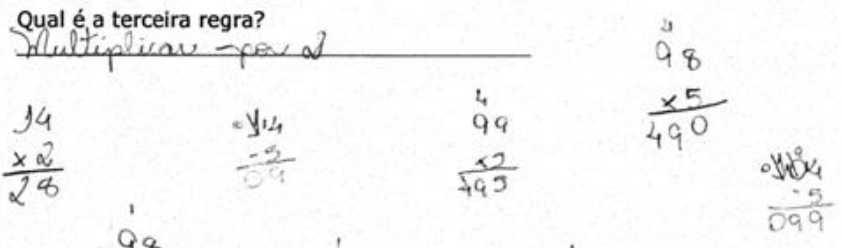

Figura 3-Registro escrito (tarefa 6) do participante E.13

(Fonte: Autores do artigo, segundo dados de pesquisa) 


\begin{tabular}{|c|c|c|c|}
\hline & \multicolumn{3}{|c|}{ Agora você cria a regra... } \\
\hline & \multicolumn{3}{|c|}{ Saida } \\
\hline Entrada & $1^{\text {a }}$ regra +3 & $2^{a}$ regra -2 & $3^{a}$ regra $\times 2$ \\
\hline 100 & 103 & 101 & 202 \\
\hline 101 & 104 & 102 & 204 \\
\hline 10 & 13 & 11 & 22 \\
\hline 11 & 14 & 12 & 24 \\
\hline 13 & 16 & 14 & 28 \\
\hline 6 & 9 & 7 & 14 \\
\hline 15 & 18 & 16 & 32 \\
\hline 6 & 9 & 7 & 14 \\
\hline$n$ & +3 & -2 & $\times 2$ \\
\hline
\end{tabular}

Qual é a primeira regra? Ma

Qual é a segunda regra? menos.

Qual é a terceira regra? multiplican be

Figura 4-Registro escrito (tarefa 6) do participante E.15

(Fonte: Autores do artigo, segundo dados de pesquisa)

As resoluções dos estudantes E.14 (que pertence ao subagrupamento $C_{3}$ ), E.25 e E.33 (ambos pertencentes ao subagrupamento $A_{1}$ ) assinalam características de pensamento algébrico, pois para o valor de entrada ' $n$ ' expressam um processo de generalização, sendo que "[...] desenvolvem algum tipo de processo de generalização; percebem e tentam expressar regularidades ou invariâncias; desenvolvem/criam uma linguagem mais concisa ou sincopada ao expressar-se matematicamente [...]" (FIORENTINI, FERNANDES; CRISTÓVÃO, 2005, p.5).

Na sequência incluímos alguns exemplos do que foi indicado no parágrafo anterior. 
Agora você cria a regra...

\begin{tabular}{|c|c|c|c|}
\hline & \multicolumn{3}{|c|}{ Saida: } \\
\hline Entiada & $1^{\text {a }}$ regra & $2^{a}$ regra & $3^{a}$ regra \\
\hline 100 & $60=$ & 206 & 205 \\
\hline 101 & 104 & 208 & 207 \\
\hline 10 & 13 & 26 & 25 \\
\hline ds & 14 & 28 & 27 \\
\hline 4 & 7 & 14 & 13 \\
\hline 3 & 16 & 7 & 14 \\
\hline 15 & 18 & 36 & 35 \\
\hline 6 & 9 & $16^{\circ}$ & 17 \\
\hline$n$ & $N+3$ & $N \times z$ & N-1 \\
\hline
\end{tabular}

Qual é a primeira regra?

Qual é a segunda regra?

Qual é a terceira regra?

Figura 5 - Registro escrito (tarefa 6) do participante E.14

(Fonte: Autores do artigo, segundo dados de pesquisa)

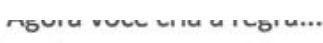

\begin{tabular}{|c|c|c|c|}
\hline & \multicolumn{3}{|c|}{ Saida } \\
\hline Entrada & $1^{\mathrm{a}}$ regra & $2^{a}$ regra & $3^{a}$ regra \\
\hline 100 & +51105 & $x a / 210$ & $-3 / 207$ \\
\hline 101 & +5106 & $\times 2206$ & $-=203$ \\
\hline 10 & +515 & $\begin{array}{r}\times 30 \\
\end{array}$ & -327 \\
\hline 1 & $+14 / 5$ & $\times 230$ & -327 \\
\hline 2 & $x \leq 7$ & $\begin{array}{r}\times 1428 \\
\end{array}$ & -325 \\
\hline 4 & +59 & $\times 2128$ & $-\quad 1414$ \\
\hline 15 & 4520 & \begin{tabular}{l|l}
$\times .40$ \\
\end{tabular} & -3137 \\
\hline 6 & +511 & $\times 22$ & -320 \\
\hline$n$ & $+5 n$ & $\times a n$ & $-3 n$ \\
\hline
\end{tabular}

Qual é a primeira regra?

Qual é a segunda regra?

Qin. tiolican

Qual é a terceira regra?

Figura 6 - Registro escrito (tarefa 6) do participante E.25

(Fonte: Autores do artigo, segundo dados de pesquisa)

DOI: Em andamento. 


\begin{tabular}{|c|c|c|c|}
\multicolumn{4}{c|}{ Agora você cria a regra... } \\
\cline { 2 - 4 } & \multicolumn{3}{c|}{ Saida } \\
\hline Entrada & $1^{\text {a } \text { regra }+3}$ & $2^{\text {a }}$ reggra & 3a regra \\
\hline 100 & 103 & 98 & 108 \\
\hline 101 & 104 & 99 & 109 \\
\hline 10 & 13 & 6 & 16 \\
\hline 11 & 14 & 9 & 19 \\
\hline 16 & 19 & 14 & 24 \\
\hline 6 & 9 & 4 & 14 \\
\hline 15 & 18 & 13 & 20 \\
\hline 6 & 9 & 4 & 14 \\
\hline$n$ & $N+3$ & $N-5$ & $N+10$ \\
\hline
\end{tabular}

Qual é a primeira regra? mais 3

Qual é a segunda regra? seaves

Qual é a terceira regra? macis to.

Figura 7-Registro escrito (tarefa 6) do participante E.33

(Fonte: Autores do artigo, segundo dados de pesquisa)

Deste modo, por meio desses registros escritos percebemos que, mesmo as crianças aplicando as regras aos valores da coluna anterior, para o valor de entrada ' $n$ ', eles generalizaram, porém, diferentemente do padrão que utilizaram para completarem a tabela, o que se verifica nestas resoluções. Cabe-nos concluir que estes estudantes confirmam características de pensamento algébrico, uma vez que esse pensamento

[...] nas séries iniciais envolve o desenvolvimento de formas de pensar em atividades para as quais a álgebra sincopada pode ser usada como uma ferramenta, mas que não é exclusiva da álgebra e poderia ser resolvida sem o uso de símbolos, tal como analisar relações entre quantidades, perceber mudanças, observar estruturas, resolver problemas, generalizar, modelar, justificar, provar e prever (KIERAN, 2004, p.12, tradução nossa).

Outras situações particulares referem-se às características de pensamento algébrico que foram elencadas neste estudo, como, por exemplo, esses registros dos estudantes E.2 (que também pertence ao subagrupamento $A_{2}$, mas que traz particularidades que buscamos destacar em função dos movimentos posteriores que realizaremos durante a análise) e E.9 (um exemplar de registro que se acomoda no subagrupamento $C_{2}$ ). 


\begin{tabular}{|c|c|c|c|}
\hline Entrada & $1^{\mathrm{a}}$ regra & $2^{a}$ regra & $3^{a}$ regra \\
\hline 100 & 98 & 88 & 178 \\
\hline 101 & 99 & 89 & 179 \\
\hline 10 & 8 & 0 & 90 \\
\hline 16 & 14 & 4 & 94 \\
\hline 26 & 24 & 14 & 104 \\
\hline 316 & 114 & 104 & 14 \\
\hline 15 & 13 & 3 & 93 \\
\hline 6 & 4 & 0 & 90 \\
\hline$n$ & -2 & -10 & $+a_{2}$ \\
\hline
\end{tabular}

Qual.é a primeira regra?

Qual.é a segunda regra?

Qual é a terceira regra? Quará 9
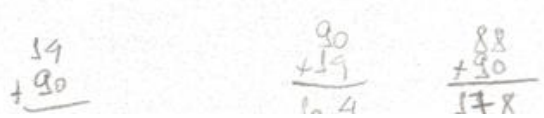

Figura 8-Registro escrito (tarefa 6) do participante E.2

(Fonte: Autores do artigo, segundo dados de pesquisa)

\begin{tabular}{|c|c|c|c|}
\hline \multicolumn{4}{|c|}{ Agora você cria a regra... } \\
\hline & \multicolumn{3}{|c|}{ Saida } \\
\hline Entrada & $1^{\mathrm{a}}$ regra +4 & $2^{a}$ regrays & $3^{a}$ regra-y \\
\hline 100 & 104 & 300 & 98 \\
\hline 101 & 1 os & 3.6 & 29 \\
\hline 10 & 14 & $3 c$ & 7 \\
\hline 10 & 14 & 30 & 7 \\
\hline 5 & gi & $14+1=15$ & 2 \\
\hline 17 & 27 & 57 & 14 \\
\hline 15 & 19 & $=5$ & 12 \\
\hline 6 & مص & 30 & 3 \\
\hline$n+4$ & 18 & 42 & 17 \\
\hline
\end{tabular}

Qual é a primeira regra?

Qual é a segunda regra?

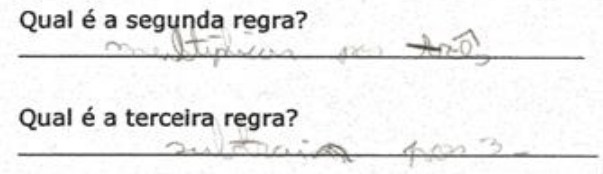

Figura 9-Registro escrito (tarefa 6) do participante E.9

(Fonte: Autores do artigo, segundo dados de pesquisa)

Como revelado, na resposta do estudante E.2 aparece o algarismo zero na terceira coluna, pois esta criança escolheu como regras: "tirar dois", "tirar dez" e "somar noventa". De tal modo, 
como aplicou as regras aos valores da coluna precedente, ao "cair" nas operações 8 'menos' 10 e 4 'menos' 10 atribuiu como resultado, o zero. Concluímos que isto se deve ao fato de que nesta fase da escolaridade não foi introduzido, aos estudantes, o conceito de números inteiros. Assim, corroboramos com Booker (2009) ao mencionar o pensamento algébrico como um "[...] meio de lidar com generalizações e maneiras de pensar, que permitam que resultados sejam expressos por meio de uma variedade de formas de problemas mais simples do que os que encontram uma resposta particular [...]" (BOOKER, 2009, p.11, tradução nossa).

O registro do estudante E.9 revela que ele aplicou as regras por ele criadas aos valores de entrada, no entanto, para o valor ' $n$ ' atribuiu um número e aplicou as regras a este valor de entrada. Um fato curioso é que na coluna referente à segunda regra faz uma adição, isto é, escreve "14 +1 = 15 ". Julgamos ser interessante esta descrição, uma vez que como a segunda regra por ele escolhida é "multiplicar por três" e tendo em vista que o valor de entrada foi " 5 " e que a tarefa já trazia o número "14" no quadro, assim aplicando a regra ao valor de entrada "cinco", teremos " 5 × $3=15$ ", logo o estudante encontrou uma saída adicionando um a quatorze (14 + 1= 15).

Ainda, podemos apontar que nestas e em outras respostas, há evidências de que estes estudantes dominam as operações aritméticas básicas, como, por exemplo, multiplicação, adição e subtração, uma vez que o quadro traz alguns valores numéricos e as crianças devem criar as regras e levar em consideração esses valores que já estão no quadro. Como exemplo relatamos a resolução do estudante E.32, tendo em vista que escolheu como regras "somar cinco", "multiplicar por dois" e "subtrair três", em que aplicou aos valores da coluna anterior. Assim, a quinta linha de valores númericos comprova esta afirmação, pois para escolher o valor de entrada o estudante deveria relacionar a primeira regra, a segunda regra e, também, o número "14", que já estava estabelecido pela tarefa. Deste modo, esta criança teve que pensar em um número que somado a cinco e multiplicado por dois daria como resultado quatorze, bem como fazer o caminho inverso. Este pensamento se assemelha à equação $(n+5) \times 2=14$. 


\begin{tabular}{|c|c|c|c|}
\hline \multicolumn{4}{|c|}{ Agora você cria a regra... } \\
\hline & \multicolumn{3}{|c|}{ Saida } \\
\hline Entrada & $1^{\text {a }}$ regra +4 & $2^{a}$ regrays & $3^{a}$ regra-3 \\
\hline 100 & 104 & 300 & 98 \\
\hline 101 & 1 os & 3.8 & 79 \\
\hline 10 & 14 & $3 c$ & 7 \\
\hline 10 & 14 & 38 & 7 \\
\hline 5 & 9 & $14+7=15$ & 2 \\
\hline 17 & 27 & 57 & 14 \\
\hline 15 & 19 & $=5$ & 12 \\
\hline 6 & 10 & 30 & 3 \\
\hline$n \times 4$ & 18 & 42 & 17 \\
\hline
\end{tabular}

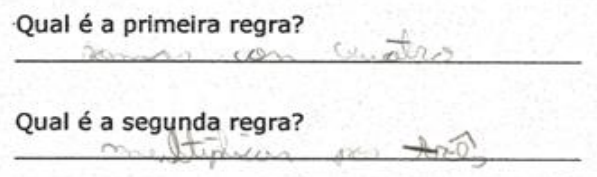

Qual é a terceira regra?

Figura 10-Registro escrito (tarefa 6) do participante E.32

(Fonte: Autores do artigo, segundo dados de pesquisa)

Concordamos com Brizuela e Schliemann (2004) ao expor que uma investigação em sala de aula com estudantes das séries iniciais apresentou que

\section{[...] os estudantes mais jovens aprendem a utilizar a notação algébrica simbólica} significativamente para expressar generalizações enquanto exploram problemas em aberto em contextos ricos. Nós descobrimos que crianças podem usar notações matemáticas não apenas para registrar o que elas compreendem, mas também para estruturar e promover o seu pensamento, permitindo a elas fazer inferências que poderiam não ter sido feitas. Nós também mostramos que a notação algébrica pode constituir uma ferramenta para generalizações, para entendimento de funções lineares e para resolução de problemas (BRIZUELA e SCHLIEMANN, 2004, tradução nossa).

De acordo com as análises, novamente julgamos ser importante realçar que um número elevado de resoluções, apresentadas pelos estudantes, não evidenciou generalizações para o valor de entrada ' $n$ ' (trinta e uma resoluções), a qual, em geral, completou com números ou então não completou. No entanto, vinte e sete registros escritos, ou seja, aproximadamente $77 \%$ confirmam um padrão ao concluírem o quadro.

Do mesmo modo, concordamos com Kieran (2004) ao assegurar que a revelação do pensamento algébrico não requer necessariamente uma linguagem simbólica algébrica e que 0

DOI: Em andamento. 
desenvolvimento deste pensamento demanda um longo processo e que se faz necessário seu início nas primeiras séries de escolaridade.

A seguir apresentaremos um quadro com as características de pensamento algébrico encontradas nas resoluções dos estudantes referente à tarefa 6 e quais os estudantes que manifestaram tais características. Informamos também que esta acomodação realizada e a busca de relações com esta nova acomodação e nossos objetivos de pesquisa fizeram com que cada uma dessas descrições de características de pensamentos, passasse a ser considerada base de emersão das categorias construídas e que contribuíram com nossas considerações finais desta investigação.

Quadro 2 - Síntese das características de pensamento algébrico encontradas nas resoluções dos estudantes referente à tarefa 6

\begin{tabular}{|c|r|}
\hline Características de Pensamento Algébrico & Participantes \\
\hline $\begin{array}{r}\text { Estabelece relações/comparações entre as } \\
\text { informações descritas na tarefa e percebe e tenta } \\
\text { expressar as estruturas aritméticas da situação- } \\
\text {-problema. }\end{array}$ & $\begin{array}{r}\text { E.20; E.21; E.22; E.23; E.24; E.25; E.26; E.27; E.28; } \\
\text { E.29; E.30; E.31; E.32; E.33 }\end{array}$ \\
\hline Desenvolve uma linguagem mais concisa & E.14; E.25; E.32; E.33 E.7; E.8; E.9; E.10; \\
ao expressar-se matematicamente. & E.14; E.25; E.32; E.33 \\
\hline Demonstra algum tipo de processo de & \\
generalização. & E.1; E.2; E.4; E.6; E.7; E.8; E.9; E.10; E.12; \\
\hline Percebe e tenta expressar regularidades ou & E.13; E.14; E.15; E.17; E.19; E.20; E.21; E.22; E.24; \\
invariâncias. & E.25; E.26; E.27; E.28; E.29; E.30; E.31; E.32; E.33 \\
\hline
\end{tabular}

(Fonte: Autores do artigo, segundo dados de pesquisa)

Diante da observação desse quadro, cabe-nos afirmar que esses estudantes investigados têm condições de lidar e de desenvolver aspectos relacionados ao pensamento algébrico, de modo que este pode ser desenvolvido antes de o estudante apresentar uma linguagem simbólica algébrica. Ficou evidente que esses estudantes investigados utilizaram notações que foram adotadas como ferramentas a fim de resolverem as tarefas propostas.

A partir desses novos grupamentos dos registros dos estudantes, segundo características próprias dos 35 estudantes investigados, passamos a observar cada grupo particularmente, ou seja, ao focarmos nas resoluções próximas ou semelhantes demos continuidade aos procedimentos propostos pela Análise de Conteúdo com o objetivo de "[...] fornecer, por condensação, uma representação simplificada dos dados brutos [...]" (BARDIN, 2004, p.112-113), o que nos levaria à

126 DOI: Em andamento.

R. Bras. de Ensino de C\&T 
condição de construir categorias que representassem esses agrupamentos prévios e estivessem relacionadas com os objetivos da tarefa e com a questão de pesquisa em foco.

Considerando que as categorias congregam elementos comuns, "[...] sob um título genérico, agrupamento esse efetuado em razão dos caracteres comuns destes elementos [...]" (BARDIN, 2004, p.111), bem como as características de pensamento algébrico nas produções escritas dos estudantes, demos continuidade à nossa retomada de todos os registros, focando-os aos grupos.

Desse 'novo' movimento interpretativo abstraímos quatro categorias (relacionadas a seguir) que foram construídas segundo critérios semânticos de aproximação dos registros, ou seja, acomodamos em uma mesma categoria as descrições das resoluções cujos registros que as compunham tivessem relação de significado com a definição de pensamento algébrico considerado para este estudo:

- Estabelecimento de relações/comparações entre as informações da situação-problema;

- Utilização de diferentes notações/representações;

- Generalização;

- Regularidades.

Retomando novamente todos os 35 registros relativos à tarefa 6, contudo, agora, desencadeando uma leitura e interpretação grupo a grupo, procuramos acomodá-los nas quatro categorias geradas. Cabe esclarecer que para essa acomodação não consideramos a exclusão mútua (em virtude do que foi observado nos dados), uma vez que uma mesma unidade de pesquisa pode ser interpretada por diferentes pontos de vista.

Na sequência apresentamos uma descrição de cada uma das categorias, com os significados que nos auxiliaram neste processo de acomodação e que contribuíram com a comunicação do que compreendemos a respeito dos registros dos estudantes e do pensamento algébrico presente na produção desses registros.

\section{Categorias - Tarefa 6}

Estabelecimento de relações/comparações entre as informações da situação-problema: nesta categoria consideramos que o estudante estabelece relações e/ou comparações entre as informações descritas na tarefa; percebe e tenta expressar as estruturas aritméticas da situação-problema.

Utilização de diferentes notações/representações: nesta categoria consideramos que o estudante utiliza de diferentes notações e/ou representações para a mesma situação-problema, como, por exemplo, linguagem natural, linguagem matemática; desenvolve uma linguagem mais concisa ao expressar-se matematicamente.

DOI: Em andamento. 
Generalização: nesta categoria consideramos que o estudante demonstra indícios de algum tipo de processo de generalização ao expressar, por meio de sua produção escrita, uma linguagem simbólica algébrica.

Regularidades: nesta categoria consideramos que o estudante demonstra indícios de regularidades, por meio de sua produção escrita, ou seja, completa o quadro utilizando um padrão.

De acordo com as características de pensamento algébrico contempladas nas categorias apresentadas, nesses registros escritos os estudantes demonstram indícios de algum tipo de processo de generalização, evidenciando ainda indícios de regularidades ao completarem o quadro utilizando um padrão.

Também é possível perceber que os estudantes produzem notações que revelam características importantes de pensamento algébrico, bem como registram expressões do tipo: "n + 3"; " $n$ - 5"; " $n+10$ "; " $\mathrm{x}$ 2"; " $n$ - 1"; entre outras. Assim, quando os estudantes "[...] observam os números e as operações, e a forma como se comportam, e, a partir dessas observações, fazem generalizações, estão a construir as bases do pensamento algébrico" (NCTM, 2008, p.9).

Mesmo com dúvidas e questionamentos no momento da resolução, os registros escritos confirmam a importância da introdução e da abordagem de álgebra nas séries iniciais, a qual se faz como um "meio de lidar com generalizações e modos de pensar, que permitem que resultados devam ser expressos em uma variedade de formas de problemas" (BOOKER, 2009, p.11, tradução nossa).

Diante do exposto, enfatizamos a necessidade de experiências em sala de aula que promovam o desenvolvimento e a construção do pensamento algébrico, de modo a estimular os estudantes a pensarem, raciocinarem, construírem relações entre os números, no sentido de uma preparação para a transição da aritmética para a álgebra, que possa servir de base para os conceitos algébricos das séries seguintes e, também, um apoio ao processo de ensino e aprendizagem da matemática.

\section{Considerações finais}

Partindo-se do objetivo de refletir sobre características do pensamento algébrico em uma tarefa aplicada a estudantes dos anos iniciais, evidenciamos algumas compreensões sobre o fenômeno em função do movimento interpretativo assumido.

Podemos então, neste momento, concluir que os participantes deste estudo evidenciaram por meio de suas produções escritas características de pensamento algébrico. Em geral, confirmamos que esses estudantes estabelecem relações e comparações entre as informações descritas na tarefa; produzem mais de uma representação para uma mesma situação-problema;

128 DOI: Em andamento. 
desenvolvem algum processo de generalização; desenvolvem uma linguagem mais concisa ou sincopada ao expressar-se matematicamente.

Além disso, a maior parte da turma investigada percebeu e tentou expressar as estruturas aritméticas da situação-problema, assim como descreveu seus processos de pensamento. Como expõe Kieran (2004), o pensamento algébrico pode ser desenvolvido antes de o estudante apresentar uma linguagem simbólica, de modo que esse pensamento compreende o desenvolvimento de formas de pensar, incluindo, por exemplo, analisar relações entre quantidades, perceber mudanças, observar estruturas, resolver problemas etc.

Outro aspecto importante de se destacar diz respeito ao incômodo e ao estranhamento dos estudantes ao longo da resolução da tarefa. Talvez este fato se deva porque os estudantes resolveram a tarefa sem a intervenção do professor (neste caso um dos pesquisadores), o que originou muitas indagações, como por exemplo: "Professora, o que eu tenho que fazer?", "me explica!", "mas não está falando o que temos que fazer", "tem que fazer conta?" etc. Também, por a tarefa proporcionar um caráter "aberto", de modo que os estudantes para resolvê-la teriam que ler, interpretar e eles próprios encontrarem um caminho de resolução.

Portanto, entendemos que esses estudantes das séries iniciais confirmam características de pensamento algébrico que descrevemos anteriormente. Igualmente, demonstram ter condições de lidar e de desenvolver aspectos relacionados ao pensamento algébrico, mesmo não apresentando uma linguagem simbólica algébrica.

\section{Referências}

ARAÚJO, Elizabeth Adorno de. Influências das habilidades e das atitudes em relação à matemática e a escolha profissional. Tese de doutorado. FE - UNICAMP: Campinas, 1999. BARDIN, L. Análise de Conteúdo. 3.ed. Lisboa: Edição 70 Ltda., 2004.

BLANTON, M. L.; KAPUT, J. J. Characterizing a Classroom Practice that Promotes Algebraic Reasoning. Journal for Research in Mathematics Education, v.36, n.5, p.412-443, 2005.

BOOKER, G. Algebraic Thinking: generalizing number and geometry to express patterns and properties succinctly. Griffith University Brisbane, 2009.

BRIZUELA, B.; SCHLIEMANN, A. Ten-year-old Students Solving Linear Equations. For the Learning Mathematics, v.24, n.2, 2004.

BRIZUELA, B. M. Desenvolvimento matemático na criança: explorando notações. Porto Alegre: Artmed, 2006.

CARPENTER, T. P., M. L. FRANKE; LEVI, L. Thinking Mathematically: Integrating Arithmetic \& Algebra in Elementary School. Portsmouth, NH: Heinemann, 2003. 
CARRAHER, D. W. et al. Arithmetic and Algebra in Early Mathematics Education. Journal for Research in Mathematics Education, v.2, n.37, p.87-115, 2006.

FIORENTINI, D.; FERNANDES, F. L. P.; CRISTOVÃO, E. M. Um estudo das potencialidades pedagógicas das investigações matemáticas no desenvolvimento do pensamento algébrico. Relatório de Projeto da Fapesp [processo 03/11233-4]. FE - UNICAMP: Campinas, 2005.

FIORENTINI, D.; LORENZATO, S. Investigação em educação matemática: percursos teóricos e metodológicos. Campinas: Autores Associados, 2006.

FIORENTINI, D.; MIORIM, M. A.; MIGUEL, A. Contribuição para um repensar... a educação algébrica elementar. Pro-Posições, v.4, n.1, p.78-91, 1993.

KIERAN, C. Algebraic thinking in the early grades: What is it? The Mathematics Educator, v.8, p.139151, 2004.

LINS, R. C.; GIMENEZ, J. Perspectivas em aritmética e álgebra para o século XXI. Campinas: Papirus, 1997.

LINS, R. C.; KAPUT, J. The early development of algebraic thinking. In: Kaye Stacey; Helen Chick (Org.). The future of the teaching and learning of algebra. Dordrecht: Kluwer, p.47-70, 2004.

MURRAY, M. K. Early Algebra and Mathematics Specialists. University of Virginia Mathematics Outreach Office. School of Continuing and Professional Studies. Charlottesville, VA 22904. The Journal of Mathematics and Science - Collaborative Explorations, v.12, p.73-81, 2010.

NCTM. Princípios e Normas para a Matemática Escolar. 1.ed., 2000. Tradução Portuguesa dos Principles and Standards for School Mathematics. 2.ed. Lisboa: APM, 2008.

OLIVEIRA, Marta Kohl de. Vygotsky: aprendizado e desenvolvimento - um processo sócio-histórico. São Paulo: Scipione, 1993.

PONTE, J. P. et al. A dinâmica da aula de matemática. In: Didáctica da Matemática, cap. 4. Lisboa: DES do MEC, 1997.

VYGOTSKY, L. S. Pensamento e linguagem. Edição eletrônica: Ed. Ridendo Castigat Mores, 2001.

Daniele Peres da Silva Programa de Pós-Graduação em Ensino de Ciências e Educação Matemática - UEL. E-mail: dani-peres@hotmail.com. Com o apoio da Capes.

Angela Marta Pereira das Dores Savioli Departamento de Matemática - UEL. E-mail: angelamarta@uel.br. Com o apoio da Fundação Araucária. 
Marinez Meneghello Passos Departamento de Matemática - UEL. E-mail: marinezmp@sercomtel.com.br. Com o apoio da Fundação Araucária.

\section{Anexos}

Tarefa 1

Nome:

Data:

\begin{tabular}{|c|c|}
\hline Símbolos & Uma possibilidade de interpretacção \\
\hline$\because x_{M} \rightarrow$ & $\begin{array}{l}\text { Ontem houve relâmpagos e trovões e } \\
\text { meu cachorro estava com medo e fugiu. }\end{array}$ \\
\hline $\begin{array}{l}\dot{1} \boldsymbol{p} \\
\text { Marco } \\
\text { Érica }\end{array}$ & \\
\hline • & Eu ouvi \\
\hline 南 & \\
\hline $3+5-2$ & \\
\hline
\end{tabular}

Tarefa 1

(Fonte: http://ase.tufts.edu/education/earlyalgebra/default.asp) 
Tarefa 2

Nome: ___ Data: Os seguintes sinais podem ser encontrados em uma estação rodoviária ou
aeroporto.

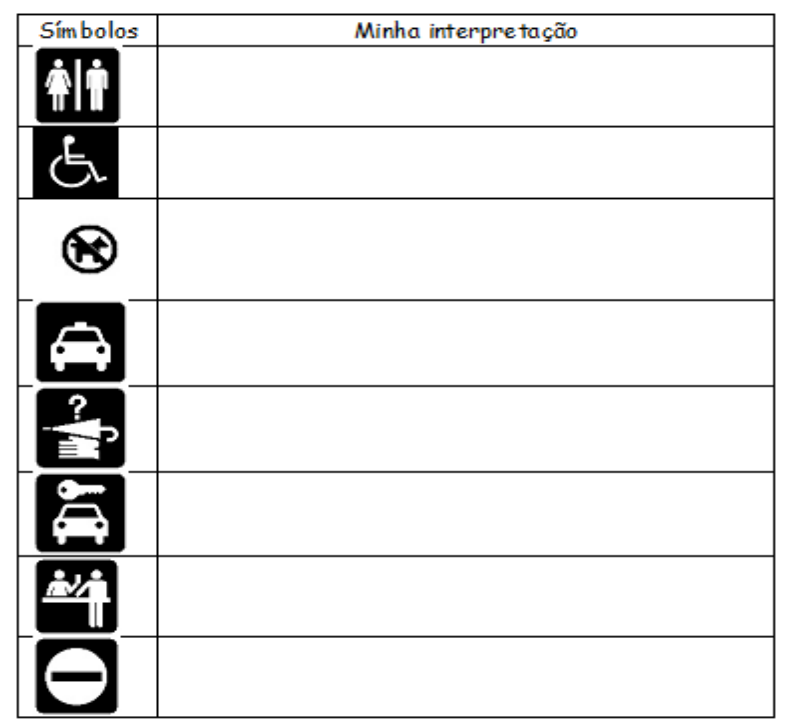

Tarefa 2

(Fonte: http://ase.tufts.edu/education/earlyalgebra/default.asp)

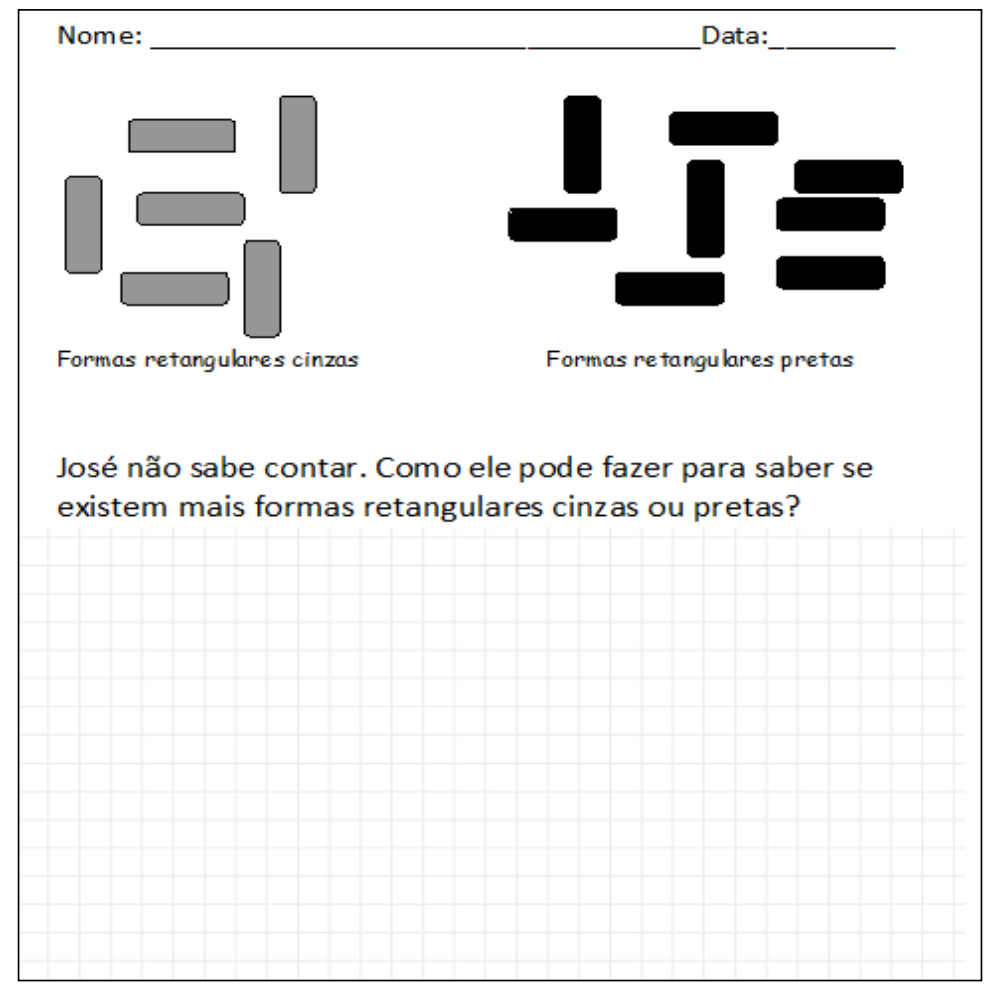

Tarefa 3

(Fonte: http://ase.tufts.edu/education/earlyalgebra/default.asp) 
Nome: Data:

João e Maria têm uma caixa de doces cada um.

João tem uma caixa e um doce em cima dela.

Maria temuma caixa e três doces em cima dela

Dentro das duas caixas têm exatamente o mesmo número de doces.

Desenhe ou escreva algo que compare quantos doces João e Maria tềm.

Tarefa 4

(Fonte: http://ase.tufts.edu/education/earlyalgebra/default.asp)

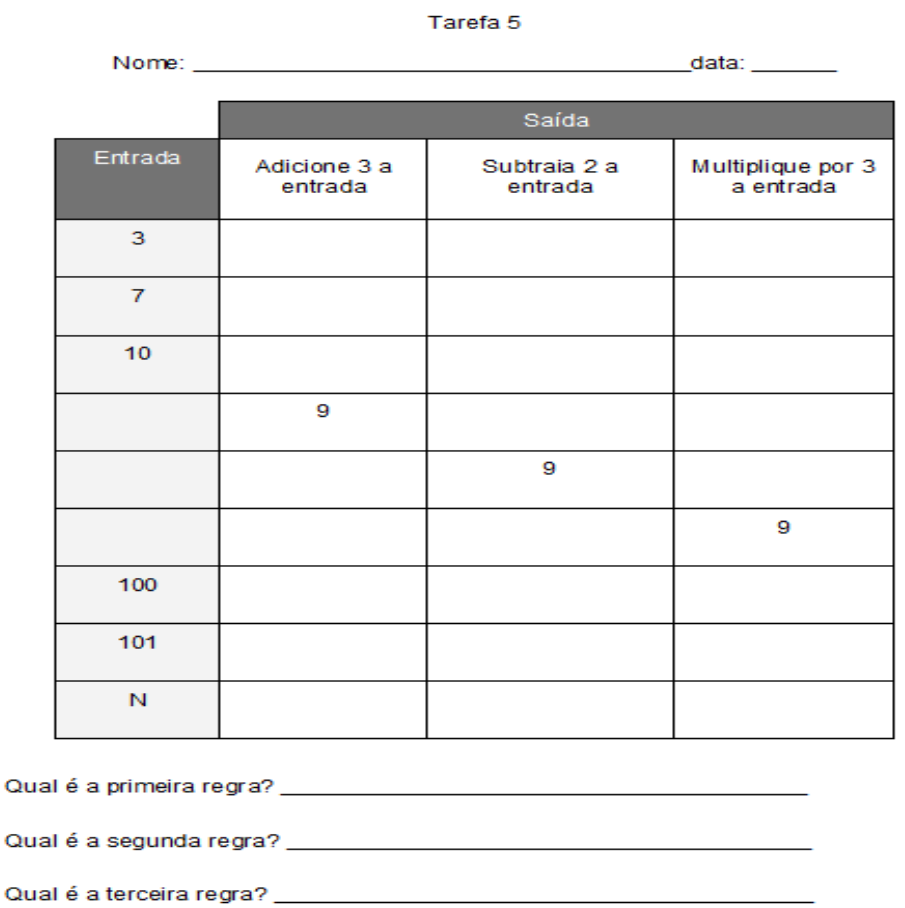

Tarefa 5

(Fonte: http://ase.tufts.edu/education/earlyalgebra/default.asp)

DOI: Em andamento. 
Tarefa 7
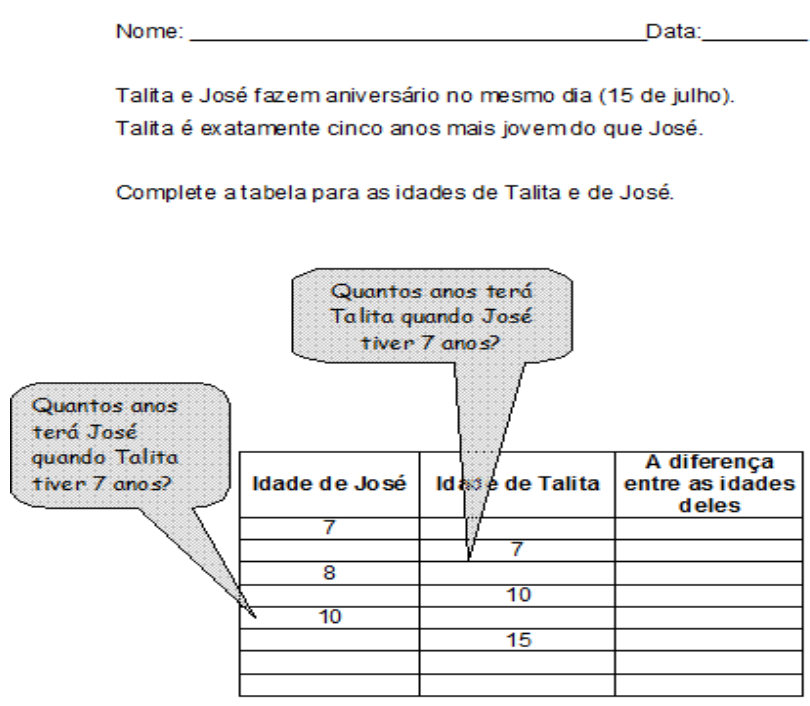

Tarefa extra:

Vamos usar a letra k para significar a idade de José.

Se José temk anos de idade, quantos anos terá Talita?

\section{Tarefa 7}

(Fonte: http://ase.tufts.edu/education/earlyalgebra/default.asp)

\section{Tarefa 8}

Nome: data

Descubra que regra segue o salto da curva na reta numerada.

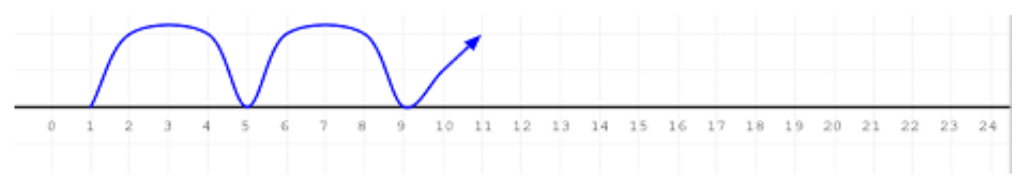

Invente uma história que envolva essa regra.

"Antes de T ony começar a trabalhar tinha R\$ 1,00 em seu cofrinho. Então, ele ganhou R \$4,00 por cada dia de trabalho."

Escreva uma expressão matemática para mostrar essa regra

\section{Tarefa 8}

(Fonte: http://ase.tufts.edu/education/earlyalgebra/default.asp) 
Enviado: 20-11-2012

Aceito: 19-06-2015

DOI: Em andamento. 